\title{
ENERGY MANAGEMENT STRATEGY OF DUAL PLANETARY HYBRID ELECTRIC VEHICLE BASED ON OPTIMAL TRANSMISSION EFFICIENCY
}

\author{
Shaohua Wang, Jiaxin Li, Dehua Shi, Xiaoqiang Sun, Yong Yao \\ School of Automobile and Traffic Engineering, Jiangsu University, Zhenjiang, China \\ e-mail: shwang@ujs.edu.cn
}

\begin{abstract}
A power split hybrid electric vehicle with dual planetary gear sets is studied in this paper. Firstly, the power split and circulation phenomenon are further described by analyzing a speed and torque relationship between the engine, motors and the output shaft based on the lever analogy. The transmission efficiency and the electric power ratio are then obtained. The working modes of the hybrid electric vehicle (HEV) are divided according to the system operation mechanism. On this basis, the engine optimal operating line (OOL) control strategy and the mechanical point (MP) control strategy are designed. Furthermore, a fuzzy controller is designed to realize the optimal torque distribution of the engine and the motors in the MP control strategy. Simulation results demonstrate that the MP control strategy can guarantee a higher efficiency of the transmission system, which also shows good performance in improving fuel economy of the HEV by adjusting the engine operating point.
\end{abstract}

Keywords: power split hybrid electric vehicle, mechanical point, fuzzy torque distribution, fuel economy

\section{Introduction}

Hybrid electric vehicles can be divided into three categories: the series type, the parallel type and the parallel-series type. In general, the parallel-series type, which consists of planetary gear sets, can simplify the power coupling mechanism effectively because the engine speed and torque are decoupled from those of the wheels (Sheu, 2008; Andaloro et al., 2017). The parallel-series system splits the engine power into the mechanical path and the electrical path. The engine directly transmits power to the wheels via the mechanical path, and the engine power is converted into electricity to drive the vehicle or charge the battery through the electrical path (Okamura et al., 2003). In the power split system, the virtual forces with different degrees of freedom were studied in planetary gear sets to determine the direction of power flow. The power circulation phenomenon was also analyzed in the transmission system (Chen and Liang, 2011). In order to improve the efficiency of the vehicle transmission system, the power flow was analyzed to obtain a relationship between the circulation power and the speed ratio (Gupta and Ramanarayanan, 2013). In addition, different transmission ratios can be obtained by changing the motion state of the components in a single-mode power split hybrid vehicle. Different power split modes of the dynamic system can also be obtained by changing transmission ratios in a dual-mode power split hybrid vehicle (Wang, 2014b).

To reduce fuel consumption and emission, fuzzy algorithm is used in parallel hybrid vehicles with only one motor to improve fuel economy, but the fuzzy algorithm is not used in the planetary platoon structure (Schouten et al., 2002). However, the single-mode power split hybrid vehicle has some drawbacks in spite of some advantages. Because the one-mode power coupling device with a single planetary gear set allows only for one node point, and as the vehicle loading increases, the power flow through the powertrain moves away from this efficiency peak point (Wishart 
et al., 2007). The complicated control strategy and the energy conversion of mechanical and electrical paths also decrease the transmission efficiency and hinder the improvement of engine performance (Schulz, 2004). To overcome those drawbacks, multi-mode power split systems, which consist of two or more than two planetary gear sets integrated with clutches and/or brakes, were studied (Yu et al., 2012). The dual-planetary hybrid powertrain has an advantage in reducing vehicle fuel consumption (Zhuang et al., 2016). However, it also affects the efficiency of the vehicle transmission system owing to complexity of the dual-mode power split system (Wang et al., 2017). The engine optimal operating line (OOL) control strategy is designed based on the fuzzy theory (Song, 2014). Although the OOL control strategy is easy to be implemented and can narrow the engine operation points around the OOL, it cannot fully improve the vehicle transmission efficiency. Therefore, the control algorithm whose fuel economy can be greatly improved is designed for the power split hybrid vehicle based on instantaneous optimization (Wang, 2014a). However, characteristics of planetary gear sets are not taken into consideration. As a result, a control strategy based on the mechanical point is designed to improve the efficiency of the whole vehicle transmission system. The ideal speed of the engine can be obtained by coordinating the change of the transmission ratio with the motor. The transmission ratio is called the mechanical point when the output power is supplied directly by the engine and no electric power. Nevertheless, the low efficiency of the engine has not been further solved on the basis of mechanical point (Kang et al., 2012; Kim et al., 2008).

For the dual planetary gear coupling mechanism, in order to ensure the high transmission efficiency and solve the problem of low efficiency of the engine at the same time, a kind of compound power split transmission system is studied in this paper. To improve the vehicle transmission efficiency, the MP control strategy is designed based on the analysis of the transmission efficiency and electric power ratio. Furthermore, the efficiency of the engine was improved by the fuzzy strategy. Simulation results for the power split hybrid electric vehicle are evaluated and compared with the simulation results of two different control strategies suggested in this study.

\section{Mechanical point analysis}

The power coupling mechanism is shown in Fig. 1. It consists of an engine, two motors and planetary gears. The engine is connected with front planet carrier $\mathrm{C} 1$ through clutch CR1 and brake CB1. The purpose of adding clutch CR1 is to reduce the effect of engine inertia and protect the engine when the vehicle is running. Motor MG1 is connected to front sun gear S1, and motor MG2 is connected to rear sun gear S2 through clutch CR2. The front planet carrier C1 is connected to rear ring gear $\mathrm{R} 2$, and front ring gear $\mathrm{R} 1$ is connected to the rear planet carrier $\mathrm{C} 2$. The power is output from the output shaft.

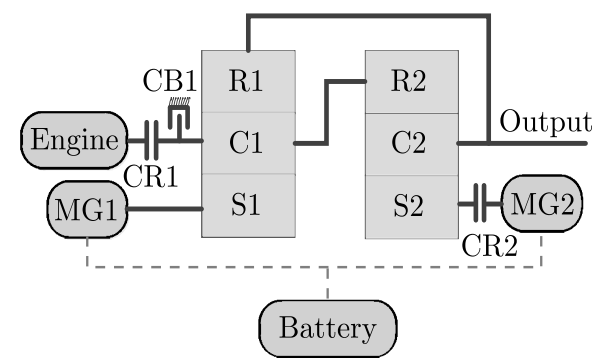

Fig. 1. Power split hybrid electric vehicle

In the paper, steady-state analysis of the power coupling mechanism is carried out using the lever method (Kim et al., 2010). The equivalent lever diagram is shown in Fig. 2. The lever distance from the engine to the output is assumed to be 1 , while the lever distance from MG1 
to the engine is set to be $a$, and the lever distance from MG2 to the output is defined as $b$. The lever model shown in Fig. 2 is a two degree-of-freedom system. The mechanical point can be obtained when the speed of MG1 or MG2 becomes zero (Wang et al., 2015). Therefore, there are two mechanical points in the power coupling system, and the vehicle efficiency range can be extended.

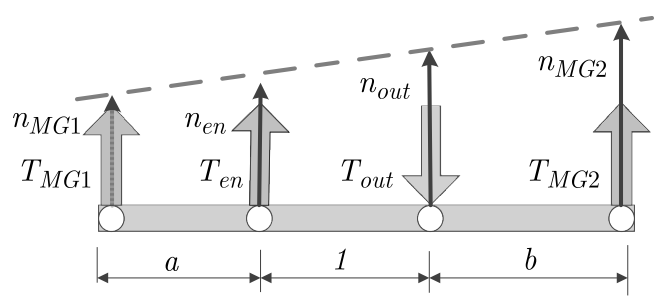

Fig. 2. Lever model of the power split HEV system

According to the relationship between the planetary gear speed and torque balance, the equivalent steady-state equation can be obtained when the rotational inertia of each component is ignored

$$
\begin{array}{ll}
n_{M G 1}+a n_{\text {out }}-(1+a) n_{\text {en }}=0 & T_{M G 1}+T_{\text {en }}+T_{M G 2}-T_{\text {out }}=0 \\
n_{M G 2}+b n_{\text {en }}-(1+b) n_{\text {out }}=0 & T_{M G 2}(1+b)-T_{M G 1} a-T_{\text {out }}=0
\end{array}
$$

where $n_{M G 1}$ is speed of motor $1, n_{M G 2}$ is speed of motor $2, n_{\text {en }}$ is engine speed, $n_{\text {out }}$ is output shaft speed, $T_{e n}$ is engine torque, $T_{M G 1}$ is torque of motor $1, T_{M G 2}$ is torque of motor $2, T_{\text {out }}$ is output torque.

In the hybrid drive process, defining the engine as a power source for the output work and assuming the output power of the battery to be zero, according to the power balance $P_{M G 1}=-P_{M G 2}($ Yao, 2016) one obtains

$$
\begin{array}{ll}
\frac{2 \pi T_{M G 1} n_{M G 1}}{\eta_{M G 1}}+2 \pi T_{M G 2} n_{M G 2} \eta_{M G 2}=0 & P_{M G 1}>0 \\
\frac{2 \pi T_{M G 2} n_{M G 2}}{\eta_{M G 2}}+2 \pi T_{M G 1} n_{M G 1} \eta_{M G 1}=0 & P_{M G 1}<0
\end{array}
$$

where $P_{M G 1}$ and $P_{M G 2}$ represent power of MG1 and MG2, respectively, $n_{M G 1}$ and $n_{M G 2}$ represent efficiency of MG1 and MG2, respectively.

In the simulation, it is assumed that the efficiency of MG1 and MG2 is 0.85 (Du et al. 2015; Kang et al., 2011). Consequently, the transmission efficiency $F(i)$, the electric power ratio $E(i)$ and the transmission ratio $i$ are defined as

$$
i=\frac{n_{\text {en }}}{n_{\text {ou }}} \quad F(i)=\frac{P_{\text {out }}}{P_{\text {en }}} \quad E(i)=\frac{P_{\text {elc }}}{P_{\text {en }}}
$$

where $P_{\text {out }}$ is vehicle output power, $P_{\text {en }}$ is engine output power, $P_{\text {elc }}$ is electrical output power. The characteristic parameters of the front and rear planetary gear set are selected as 1.842 and 2.48 , respectively. Namely, $k_{1}=1.842, k_{2}=2.48$. The ratio of the speed and torque of the two motors to the engine are shown in Fig. 3. When MG2 torque or MG1 speed is zero, the electric power is zero, and the first mechanical point $i_{1}$ is obtained. The mechanical point $i_{2}$ can be obtained when MG1 torque or MG2 speed is zero. It can be seen that the transmission ratio $i$ will decrease with an increase in the vehicle speed if the engine speed is constant. The direction of MG1 speed is the same as the direction of the engine speed when $i>i_{1}$. When $i<i_{1}$, the direction of MG1 is opposite to the direction of the engine speed, and the torque of MG1 is positive when $i>i_{2}$; MG1 torque is negative when $i<i_{2}$. Therefore, the power of MG1 is 
negative when $i_{1}<i<i_{2}$; the power of MG1 is positive when $i<i_{1}$ and $i>i_{2}$. Similarly, the power of MG2 is positive when $i_{1}<i<i_{2}$, and the power of MG2 is negative when $i<i_{1}$ and $i>i_{2}$. In addition, it is apparent that the electric power of MG1 and MG2 is very large when the transimission ratio becomes too large or too small, which should be avoided.

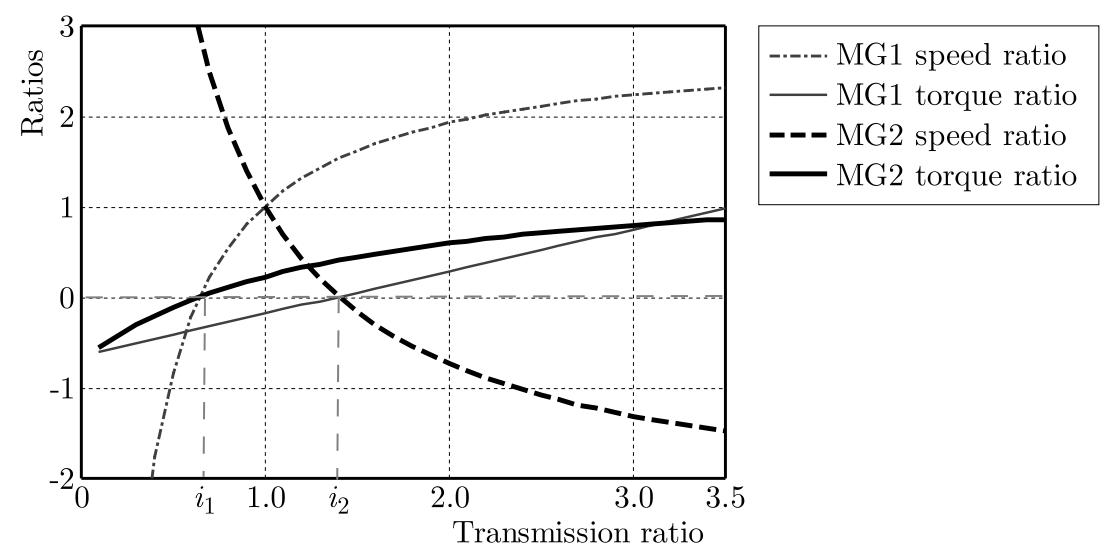

Fig. 3. Speed ratio and torque ratio

The power flow within the power coupling mechanism is shown in Figs. 4a and 4b. The power split phenomenon occurs when $i_{1}<i<i_{2}$. The direction of the power flow is shown in Fig. 4a. A part of the engine power is transmitted to the output shaft via the mechanical path, and the rest of the engine power is transmitted through the electrical path. At this time, MG1 operates in the charging state, and MG2 is in the discharging state. The power circulation phenomenon occurs when $i<i_{1}$ and $i>i_{2}$, and the power flow is shown in Fig. 4b. MG1 is in the discharging state and MG2 is in the charging state. The efficiency of vehicle transmission system is reduced (Zhang, 2015). Therefore, in order to avoid the power circulation phenomenon and ensure the high transmission efficiency, MG1 should be arranged as a generator, and MG2 should be arranged as a motor.
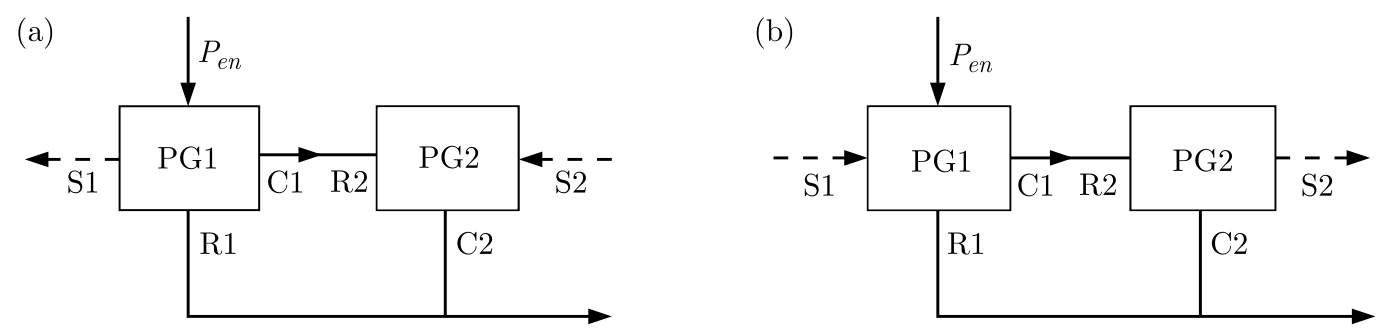

Fig. 4. (a) Power split and (b) power circulation of the power split HEV

PG1 is the front planetary gear set and PG2 is the rear planetary gear set. Figure 5 shows the transmission efficiency and electric power ratio. The left vertical coordinate is the ratio of electrical power while the right one is the ratio of transmission efficiency. It can be seen that the ratio of electric power can be zero, and the battery does not do work. However, the transmission efficiency cannot be equal to zero because the vehicle demand for power and the engine output power are neither zero when the vehicle runs and the engine is involved in the operation. Transmission efficiency of the vehicle drops rapidly as the transmission ratio decreases when $i<i_{1}$. The electrical power increases and the transmission efficiency decreases with an increase in the transmission ratio when $i>i_{2}$. The whole vehicle transmission efficiency will be higher and the electrical power will be very low if $i$ meets $i_{1}<i<i_{2}$. The engine power is directly transmitted to the output shaft through the mechanical path when the engine runs at the mechanical point, and the vehicle has the highest transmission efficiency. 


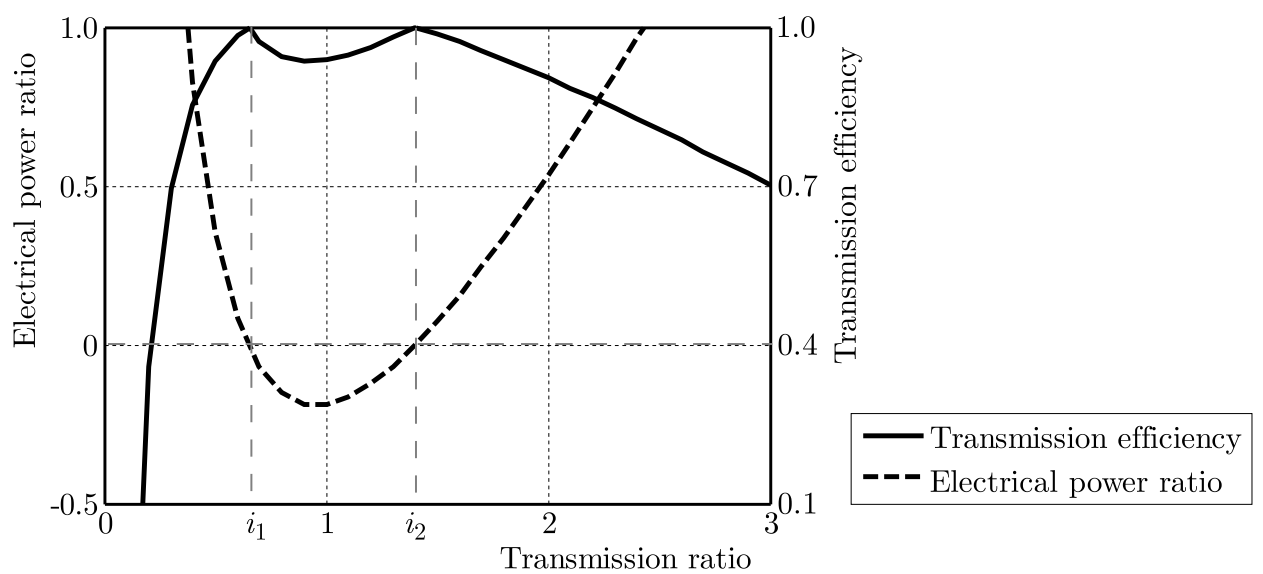

Fig. 5. Transmission efficiency and electric power ratio

\section{Working modes of the system}

According to the combination of clutch status and the participation of power components, the working modes of the proposed HEV are divided into six categories, as shown in Table 1.

Table 1. Working modes of the dual planetary hybrid electric vehicle

\begin{tabular}{|l|c|c|c|c|c|c|}
\hline \multicolumn{1}{|c|}{ Mode } & Engine & MG1 & MG2 & CR1 & CR2 & CB1 \\
\hline \hline Pure electric mode & 0 & 0 & 1 & 0 & 1 & 1 \\
\hline Hybrid drive mode & 1 & 1 & 1 & 1 & 1 & 0 \\
\hline Regenerative braking mode & 0 & 0 & 1 & 0 & 1 & 1 \\
\hline Mechanical braking mode & 0 & 0 & 0 & 0 & 0 & 0 \\
\hline Charging standstill mode & 1 & 1 & 0 & 1 & 0 & 0 \\
\hline Parking mode & 0 & 0 & 0 & 0 & 0 & 0 \\
\hline
\end{tabular}

Note: 1 indicates the working status, 0 means the no working condition

Figure 6a shows the equivalent lever diagram in the pure electric mode. The front carrier gear C1 is locked when CB1 is locked. The rear sun gear S2 is connected to MG2 when CR2 is engaged. The engine does not participate in the work and MG2 drives the vehicle separately. The steady-state relationship is

$$
T_{M G 2}-\frac{1}{1+k_{2}} T_{\text {out }}=0 \quad n_{M G 2}-\left(1+k_{2}\right) n_{\text {out }}=0
$$

Figure $6 \mathrm{~b}$ shows the equivalent lever diagram in the hybrid drive mode. CR1 is engaged in this mode, the engine and two motors output power to the wheels. The engine speed is coordinated by MG1, and MG2 acts as output torque compensation. The steady-state relation is shown as

$$
\begin{array}{ll}
n_{M G 1}+k_{1} n_{\text {out }}-\left(1+k_{1}\right) n_{\text {en }}=0 & T_{M G 1}+T_{\text {en }}+T_{M G 2}-T_{\text {out }}=0 \\
n_{M G 2}+k_{2} n_{\text {en }}-\left(1+k_{2}\right) n_{\text {out }}=0 & T_{M G 2}\left(1+k_{2}\right)-T_{M G 1} k_{1}-T_{\text {out }}=0
\end{array}
$$

Figure $7 \mathrm{a}$ shows the equivalent lever diagram in the regenerative braking mode. CR2 and $\mathrm{CB} 1$ are engaged and the rear sun gear is connected to MG2. In this mode, the braking energy is regenerated by MG2 and stored in the battery. It is an effective way to realize energy conservation and decrease emission of the HEV. The steady-state relation is

$$
T_{M G 2}\left(1+k_{2}\right)-T_{\text {out }}=0 \quad n_{M G 2}-\left(1+k_{2}\right) n_{\text {out }}=0
$$


(a)

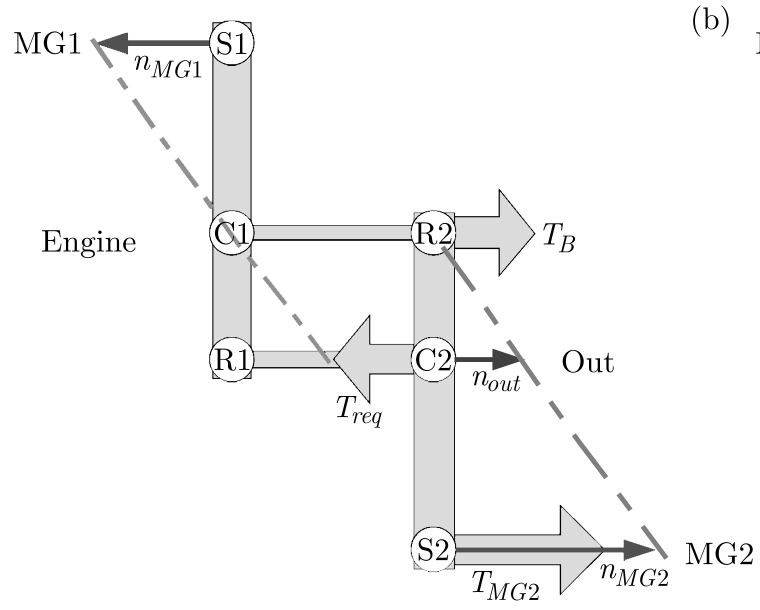

(b)

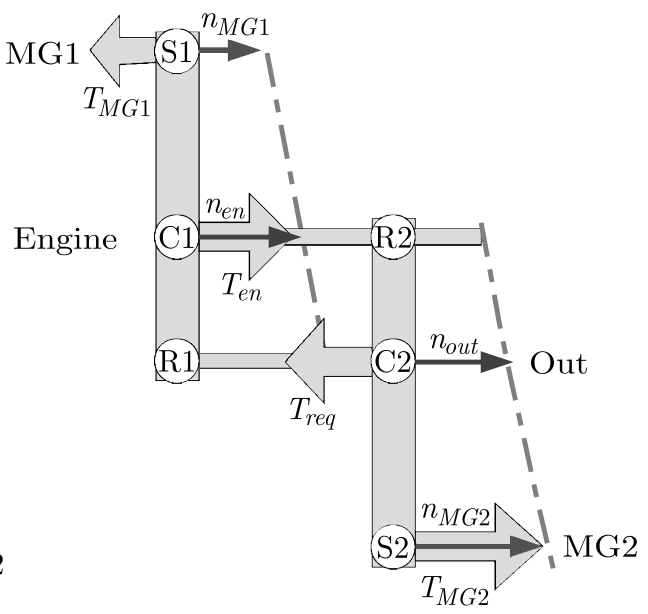

Fig. 6. (a) Pure electric mode, (b) hybrid drive mode

Figure $7 \mathrm{~b}$ shows the equivalent lever diagram in the charging standstill mode. The engine outputs power to drive MG1 when CR1 is engaged. In this way, the battery $S O C$ is maintained at the appropriate range. This is very beneficial to ensure a long battery life and improve fuel economy. The steady-state relation is

$$
T_{M G 1}+\frac{1}{1+k_{1}} T_{e n}=0 \quad n_{M G 1}-\left(1+k_{1}\right) n_{e n}=0
$$

(a)

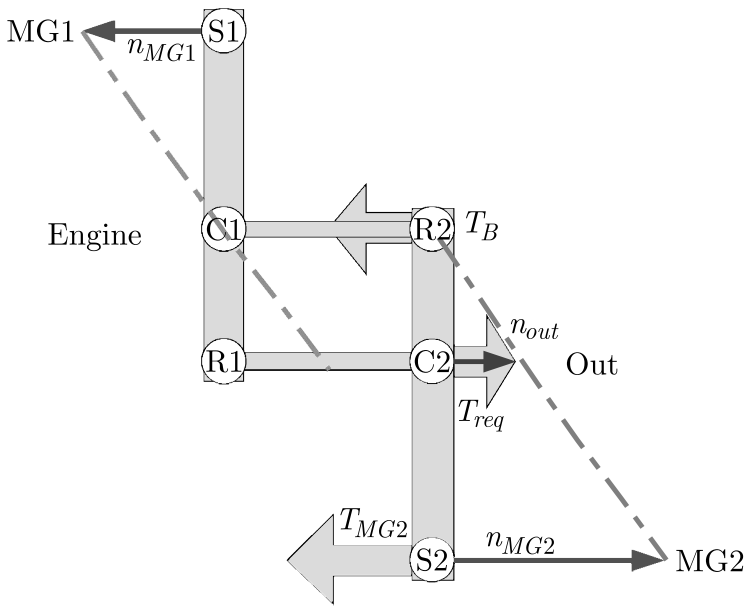

(b)

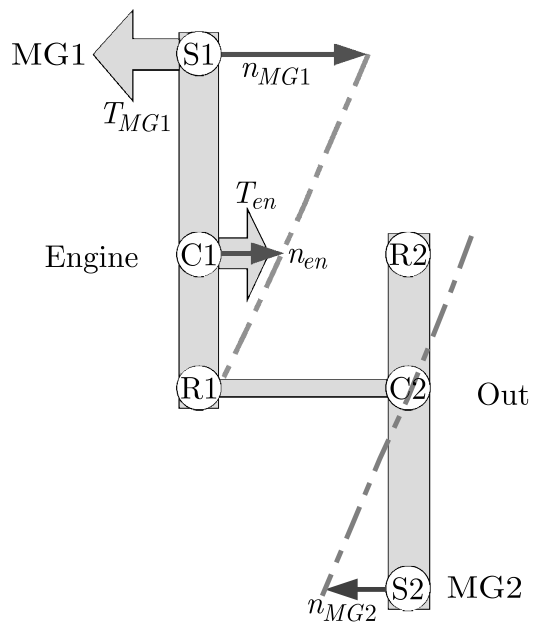

Fig. 7. (a) Regenerative braking mode, (b) charging standstill mode

\section{Control strategy}

The control strategy is divided into two parts: mode recognition and torque distribution. In this paper, the rule-based control strategy, which has good robustness and real-time performance, is designed (Zhao and Ma, 2014). In the mode recognition module, the operation modes of the HEV are decided according to the predefined thresholds, and the vehicle will switch to another mode if the vehicle state variable satisfies the switching condition. In the torque distribution module, the OOL control strategy and the MP control strategy are adopted respectively. Table 2 gives the control rules of the vehicle. 
Table 2. Control rules

\begin{tabular}{|l|c|}
\hline \multicolumn{1}{|c|}{ Working modes } & Jump conditions \\
\hline \hline Pure electric mode & $0<P_{\text {req }}<P_{e_{-} \min }$ and $V<V_{\text {th_ev }}$ and $S O C>S O C_{\min }$ \\
\hline Regenerative braking mode & $P_{\text {req }}<0$ and $V<V_{t h \_b r}$ and $S O C<S O C_{\max }$ \\
\hline Mechanical brake & $P_{\text {req }}<0$ and $\left(V>V_{t h \_b r}\right.$ or $\left.S O C>S O C_{\max }\right)$ \\
\hline Hybrid drive mode & $\left(P_{\text {req }}>P_{e_{-} \min }\right.$ or $V>V_{t h \_e v}$ or $\left.S O C<S O C_{\min }\right)$ and $t_{c l}>3 \mathrm{~s}$ \\
\hline Parking mode & $V=0$ and $S O C>S O C_{\max }$ \\
\hline Charging standstill mode & $V=0$ and $S O C<S O C_{\max }$ \\
\hline
\end{tabular}

In Table $2, P_{r e q}$ is vehicle demand power, $P_{e_{m} i n}$ is minimum engine start power, $V_{r}$ is actual speed, $V_{t h \_e v}$ is pure electric speed, $V_{t h_{-} c r}$ is cruising speed, $V_{t h \_b r}$ is regenerative brake start speed, $S O C$ is charge state of battery, $S O C_{\min }$ is $S O C$ lower limit, $S O C_{\max }$ is $S O C$ upper limit, $t_{c l}$ is taken from the last time the engine was closed.

\subsection{The OOL control strategy}

The engine can run on the optimal operating line under the OOL control strategy, which ensures a high efficiency of the engine. The optimal operating line of the engine is made up of the optimal working points. Firstly, taking $n$ power points evenly and drawing the corresponding power line in the maximum and minimum power range of the engine, the engine equal power line should be limited within the engine speed range. Furthermore, the engine efficiency of each working point is calculated on the engine equivalent power line. The most efficient points of the engine at those points are selected as the optimal working points. (Yu et al., 2007). The optimal operating line of the engine is shown in Fig. 8.

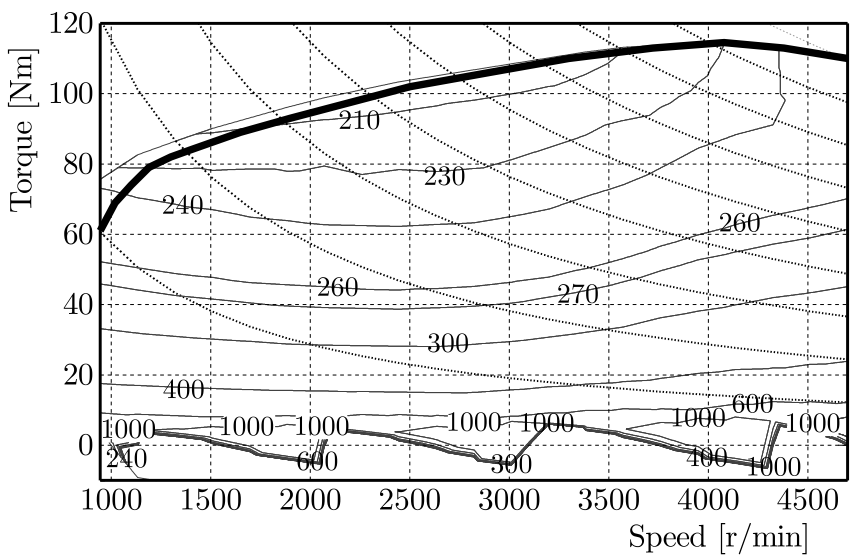

Fig. 8. The engine optimal operating line

Firstly, the engine speed can be obtained by looking up the table according to the demand power and adjusted by MG1. The engine torque is obtained from the engine optimal operating line. Then the power of MG1 and MG2 are obtained according to the steady-state relationships and a series of external characteristics constraints. The power flow is shown in Fig. 9.

\subsection{The MP control strategy}

The MP control strategy, from the angle of the optimal transmission efficiency, takes the characteristics of the planetary gear sets into account. The engine speed control strategy based on optimal transmission efficiency is adopted. When the vehicle runs in the pure electric mode and the regenerative braking mode, the engine does not participate in the work, and the motor 


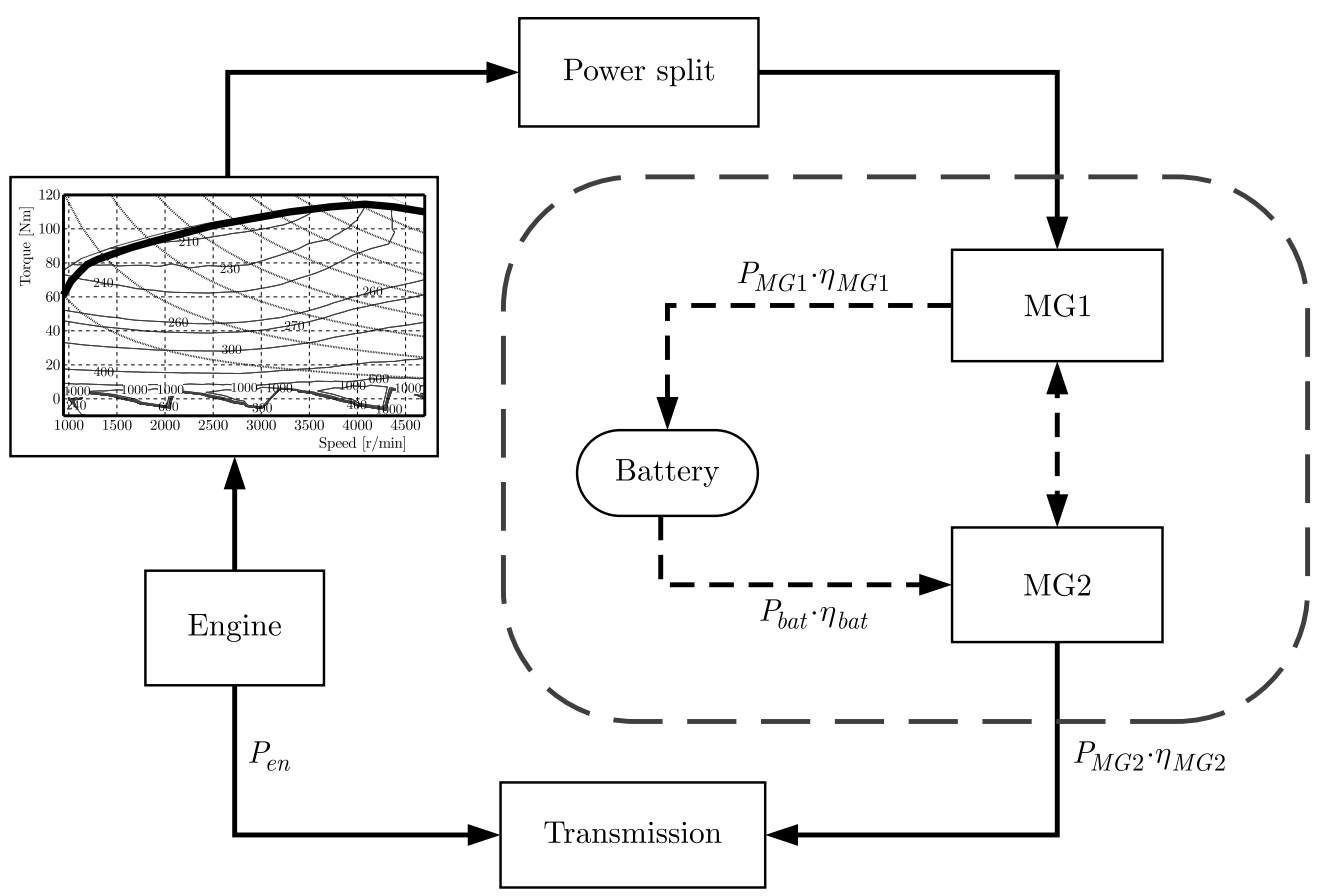

Fig. 9. Power flow of the power split HEV

is involved in the driving and braking modes. In order to simplify the control of the engine, the engine is fixed at a working point that the fuel consumption is smaller on the OOL when the vehicle runs in the charging standstill mode. As aforementioned, there is a mechanical point when the torque or speed of one of the motors is zero, where the vehicle can operate with the highest transmission efficiency. Therefore, the engine speed is regulated by MG1 to run at the machanical point when the vehicle runs in the hybrid drive mode. The principle of speed control is shown in Fig. 10. It is set to be 1.1.

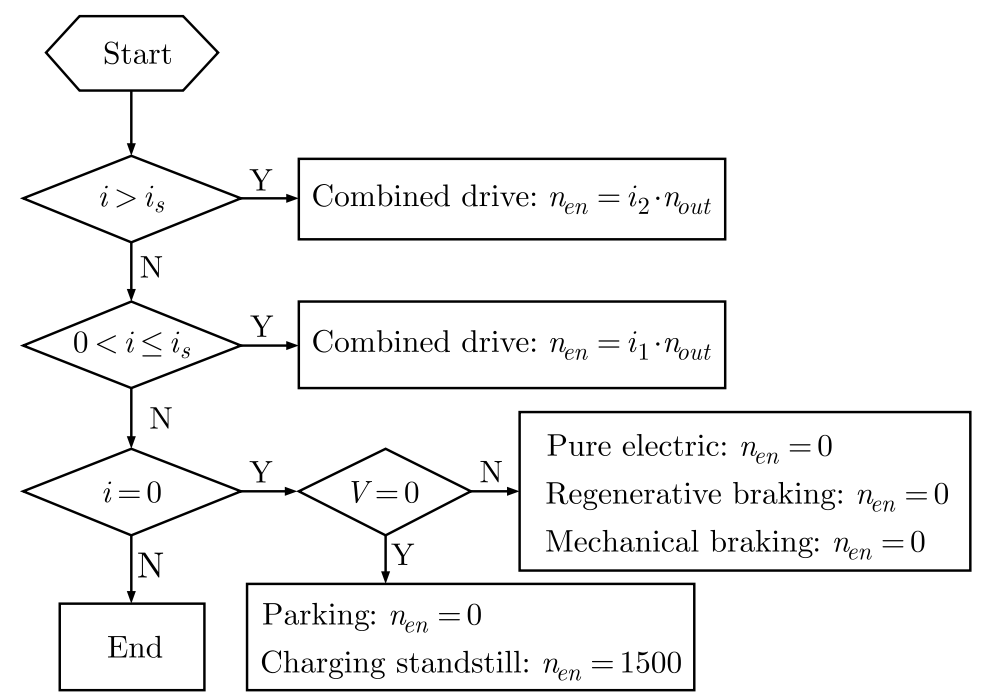

Fig. 10. Speed control of MP control straregy

In addition, in order to solve the problem of low efficiency of the engine when it runs on the mechanical point. The torque distribution strategy based on a fuzzy algorithm is used to optimize the distribution of the engine and the motors torque. The torque optimization principles are shown in Fig. 11. According to the design target of the fuzzy controller and the working 
efficiency of the engine, $q$ and $r$ are defined as input variables. $q$ is defined as the ratio of the demanded torque to the optimal torque at the current engine speed. $r$ is defined as the ratio of the current battery $S O C$ to the $S O C$ initial value. The output variable is the engine torque coefficient $k$. Domain transformation of the parameters can be realized by converting the actual physical value of the input and output variables into a proportional value (Yin et al. 2006; Langlois, 2010). The linguistic terms are expressed in fuzzy sets. Such as the variable $q$, this variable is represented by the linguistic terms VS (very small), S (small), M (middle), B (big), VB (very big). $q$ is divided into five fuzzy subsets, namely $\{\mathrm{VS}, \mathrm{S}, \mathrm{M}, \mathrm{B}, \mathrm{VB}\}$, and the domain is $[0,1.4]$. Similarly, $r$ is also divided into five fuzzy subsets, namely $\{\mathrm{VS}, \mathrm{S}, \mathrm{M}, \mathrm{B}, \mathrm{VB}\}$, and its domain is $[0,1.2]$. The engine torque coefficient $k$ is defined as the output variable which is divided into $\{\mathrm{VS}, \mathrm{S}, \mathrm{M}, \mathrm{B}, \mathrm{VB}\}$, and the domain is $[0,1.4]$.

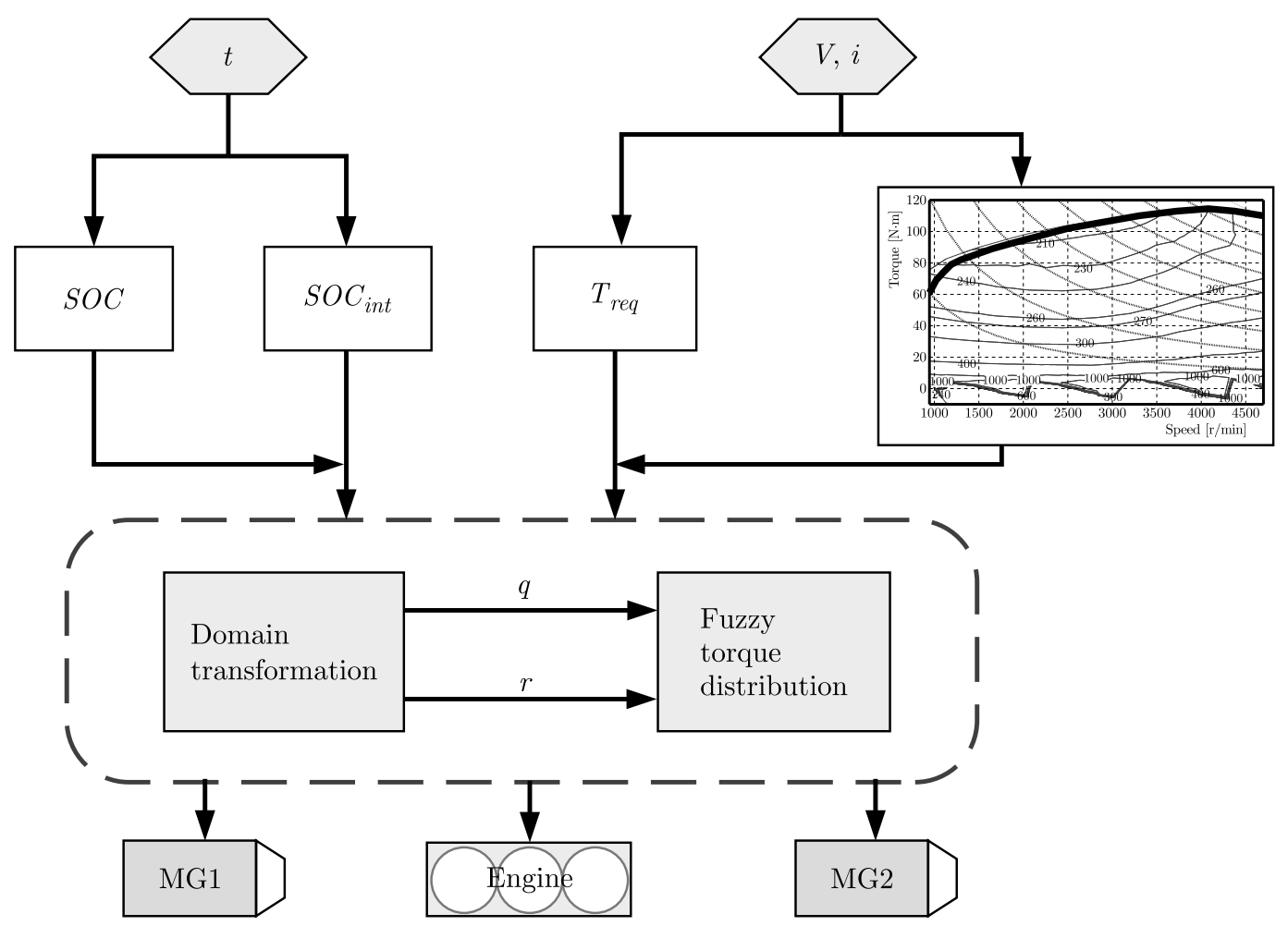

Fig. 11. Torque optimization

Table 3. Fuzzy control rules

\begin{tabular}{|c|c||c|c|c|c|c|}
\hline \multicolumn{2}{|c||}{\multirow{2}{*}{$T_{e n}$}} & \multicolumn{5}{c|}{$q$} \\
\cline { 3 - 7 } & & $\mathrm{VS}$ & $\mathrm{S}$ & $\mathrm{M}$ & $\mathrm{B}$ & $\mathrm{VB}$ \\
\hline \hline & $\mathrm{VS}$ & $\mathrm{M}$ & $\mathrm{B}$ & $\mathrm{B}$ & $\mathrm{B}$ & $\mathrm{VB}$ \\
\hline & $\mathrm{S}$ & $\mathrm{M}$ & $\mathrm{B}$ & $\mathrm{B}$ & $\mathrm{B}$ & $\mathrm{B}$ \\
\hline$r$ & $\mathrm{M}$ & $\mathrm{M}$ & $\mathrm{M}$ & $\mathrm{M}$ & $\mathrm{M}$ & $\mathrm{B}$ \\
\hline & $\mathrm{B}$ & $\mathrm{VS}$ & $\mathrm{S}$ & $\mathrm{M}$ & $\mathrm{B}$ & $\mathrm{M}$ \\
\hline & $\mathrm{VB}$ & $\mathrm{VS}$ & $\mathrm{VS}$ & $\mathrm{M}$ & $\mathrm{M}$ & $\mathrm{M}$ \\
\hline
\end{tabular}

The fuzzy sets need to be combined using the logical connectives "OR", "AND" and "NOT" to handle the fuzzy rules. Finally, the fuzzy controller is designed by the fuzzy sets and the fuzzy set operators. This is established based on the following points mainly: The engine runs near the reference torque and MG2 is used for the auxiliary drive when the $S O C$ is high and the demanded torque is large. When the $S O C$ value is low and the demanded torque is low or 
moderate, the engine is adjusted to meet the vehicle demanded torque, and the rest power of the engine drives MG1 to charge the battery. The engine output torque remains the same when the $S O C$ value is moderate and the demanded torque is moderate. The fuzzy control rules are shown in Table 3.

\section{Simulation}

In order to verify the effect of two control strategies, the hybrid electric vehicle model is built in AVL/Cruise and two control strategies are constructed in MATLAB/Simulink software, and the co-simulation platform is finally established through MATLAB_DLL interface. The vehicle is tested under multiple operating conditions. The parameters of the main components are shown in Table 4.

Table 4. Main components parameters

\begin{tabular}{|c|c|c|}
\hline Part name & Parameter name & Value \\
\hline \hline \multirow{3}{*}{ Engine } & maximum power & $54 \mathrm{~kW}$ \\
\cline { 2 - 3 } & maximum speed & $4700 \mathrm{r} / \mathrm{min}$ \\
\cline { 2 - 3 } & maximum torque & $115 \mathrm{Nm}$ \\
\hline \multirow{3}{*}{ MG1 } & maximum power & $15 \mathrm{~kW}$ \\
\cline { 2 - 3 } & maximum speed & $8000 \mathrm{r} / \mathrm{min}$ \\
\cline { 2 - 3 } & maximum torque & $55 \mathrm{Nm}$ \\
\hline \multirow{3}{*}{ MG2 } & maximum power & $30 \mathrm{~kW}$ \\
\cline { 2 - 3 } & maximum speed & $12000 \mathrm{r} / \mathrm{min}$ \\
\cline { 2 - 3 } & maximum torque & $305 \mathrm{Nm}$ \\
\hline \multirow{2}{*}{ Battery } & rated voltage & $288 \mathrm{~V}$ \\
\cline { 2 - 3 } & capacity & $6.5 \mathrm{Ah}$ \\
\hline \multicolumn{2}{|l|}{ Tire dynamic radius } & $0.2928 \mathrm{~mm}$ \\
\hline Curb weight & $1260 \mathrm{~kg}$ \\
\hline \multicolumn{2}{|l|}{ Gross weight } & $1600 \mathrm{~kg}$ \\
\hline \multicolumn{2}{|l}{ Facing area } & $1.746 \mathrm{~m}^{2}$ \\
\hline
\end{tabular}

Simulation results under the NEDC condition are shown in Figs. 12-14. From Fig. 12a and Fig. 15f, it can be seen that the speed under the MP control strategy and OOL control strategy can well follow the target speed in urban and high speed conditions, and the error is within the acceptable range. The working modes are approximately the same under the two control strategies in the NEDC condition because of the predefined mode decision rules and thresholds. However, the engine starting moment under the OOL control strategy is about 17s earlier than the MP control strategy in the vicinity of $1020 \mathrm{~s}$. Figure $12 \mathrm{~b}$ shows the change line of the battery $S O C$ under two control strategies. The battery SOC decreases 0.07 under the MP control strategy, and decreases 0.08 under the OOL control strategy. However, the battery SOC varies greatly between $800 \mathrm{~s}$ and $1150 \mathrm{~s}$ under the OOL strategy, the main reason is that the output power of the motors is large and the battery power is rapidly consumed. However, the engine runs at the mechanical point in the MP strategy, which reduces the output power of the battery and makes the battery SOC fluctuate slightly. Figure 12e shows varying curves of the transmission ratio under the OOL and MP control strategies, and the difference between the two strategies can be better demonstrated between 800s and $1126 \mathrm{~s}$. The transmission ratio is obviously smaller than $i_{1}$ between $800 \mathrm{~s}$ and $1075 \mathrm{~s}$ and obviously greater than $i_{1}$ from $1090 \mathrm{~s}$ to $1126 \mathrm{~s}$. However, the engine always runs at the mechanical point during the MP control strategy, which ensures the highest transmission efficiency. In one can see that Fig. 12c MG1 outputs the power from positive to negative in the OOL control strategy, which reduces the fuel economy of 
the vehicle because of the power circulation phenomenon, and it is also one of the reasons for the rapid decline of the battery $S O C$. However, the power circulation is avoided because the power of MG1 is almost zero between $970 \mathrm{~s}$ and $1126 \mathrm{~s}$ under the MP control strategy, which ensures a higher transmission efficiency of the vehicle. From Fig. 12d and Fig. 12g, the output power of MG2 and the torque of engine in the MP strategy is significantly less than that in the OOL control strategy between $970 \mathrm{~s}$ and $1126 \mathrm{~s}$. Therefore, vehicle output power under the MP control strategy is relatively smaller and the transmission efficiency of the whole vehicle is improved effectively.

(a)

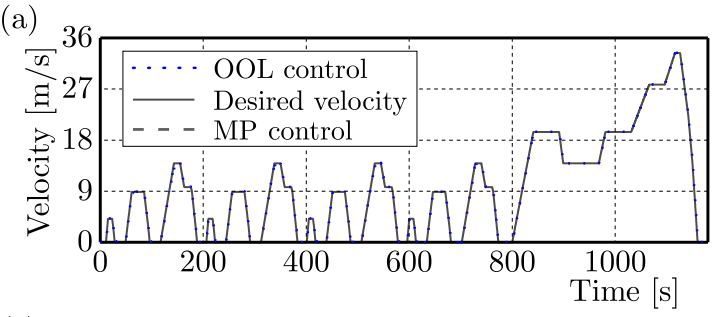

(c)

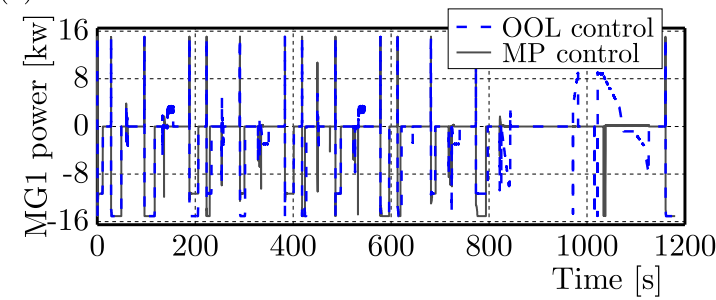

(e)

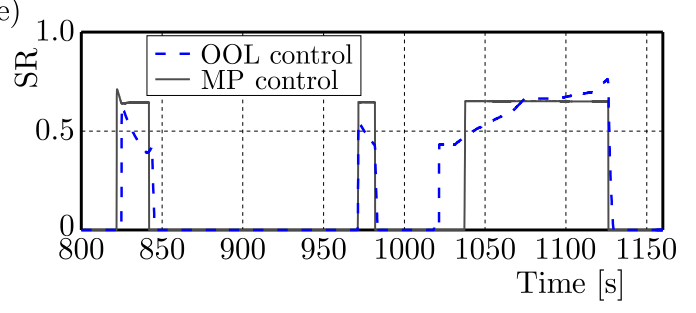

(b)

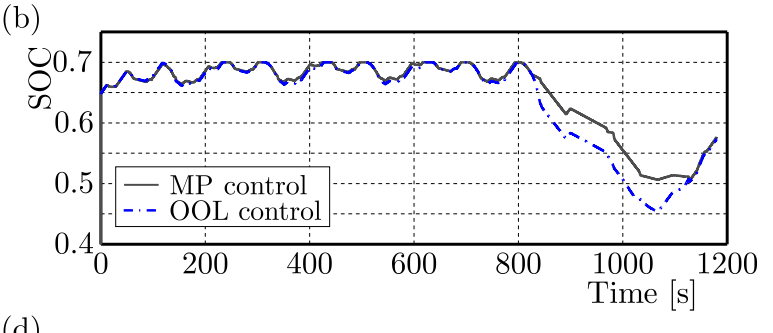

(d)

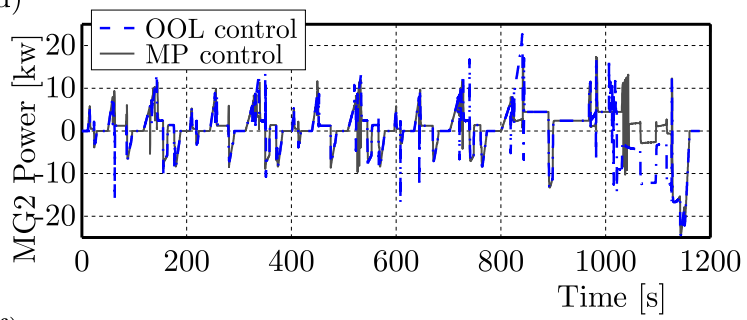

(f)

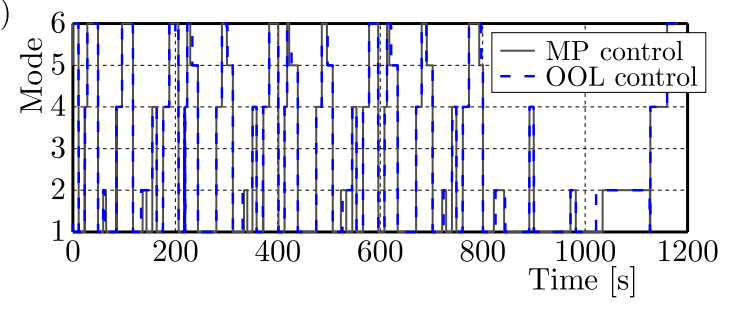

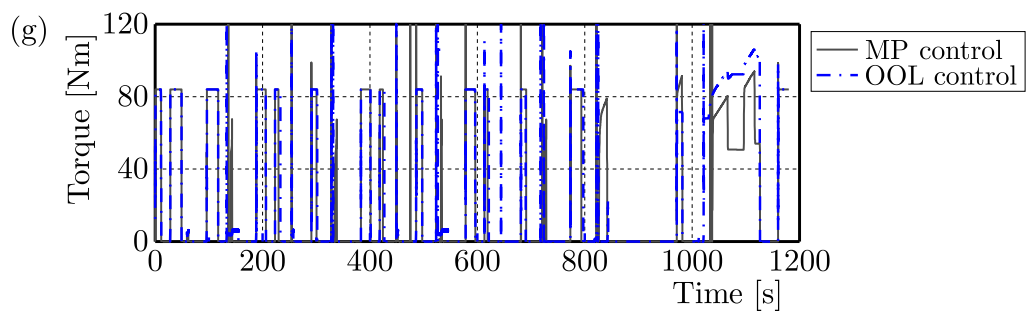

Fig. 12. Simulation comparisons

Figure 13 indicates the engine operating point under the OOL and MP control strategies. The engine always runs around the optimal operating line under the OOL strategy. The vehicle transmission efficiency is not high even though the engine operation points are located in the region with a lower fuel consumption rate under the OOL strategy. In the MP control strategy, the energy conversion loss is reduced, and the transmission efficiency is improved by changing the speed ratio and improving the engine torque with the fuzzy torque distribution method.

Table 5 shows the comparison of energy loss of various components under two control strategies. The total input energy of the engine and the battery is defined as $100 \%$. As can be seen from the table, the total input energy is about $13066.7 \mathrm{KJ}$ under the MP control strategy, which is reduced by $1390 \mathrm{KJ}$ compared with the OOL control strategy. It is mainly because that the MP strategy ensures the high transmission efficiency of the system. It is obvious that the proportion of the engine loss is the largest of all the components. Engine losses consume $8652.4 \mathrm{KJ}$ 


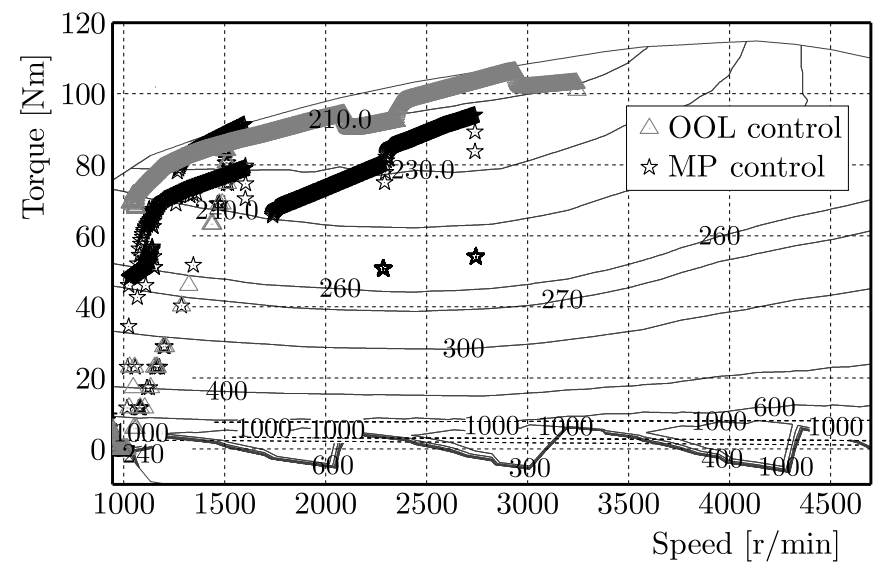

Fig. 13. Engine operating point

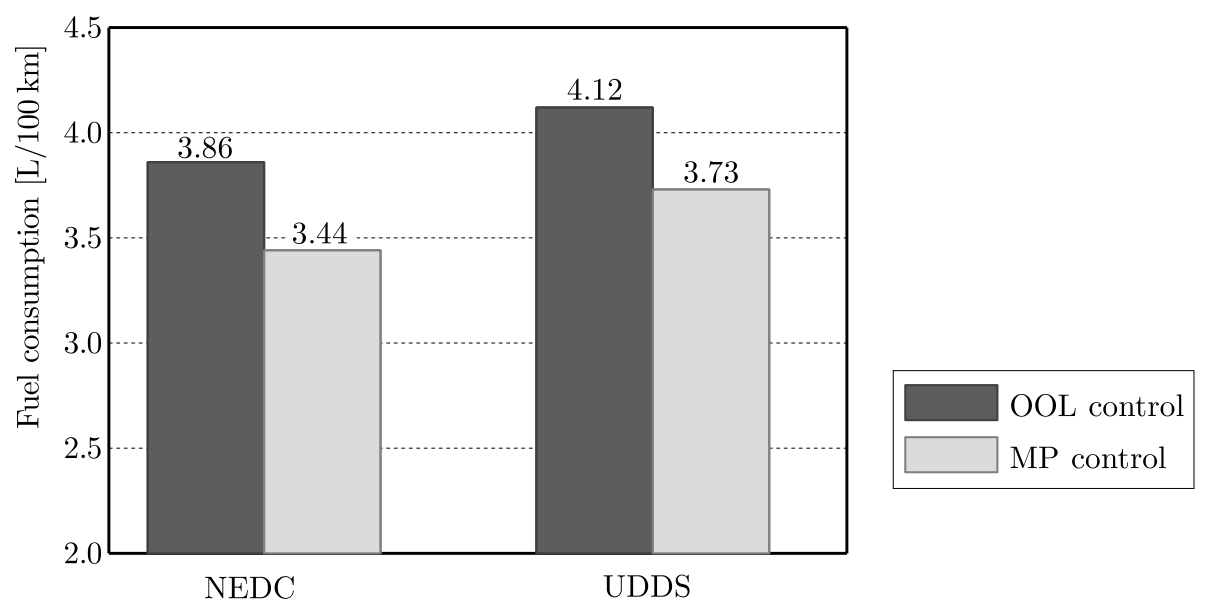

Fig. 14. Fuel consumption under NEDC and UDDS conditions

Table 5. Comparison of energy loss under two strategies

\begin{tabular}{|c|c|c|c|}
\hline \multicolumn{3}{|c|}{ OOL control strategy } \\
\hline $\begin{array}{c}\text { Power } \\
\text { sources } \\
{[\mathrm{KJ}]}\end{array}$ & \multicolumn{3}{|c|}{$\begin{array}{c}\text { Components loss } \\
\text { and } \\
\text { proportion }\end{array}$} \\
\hline \hline \multirow{2}{*}{$\begin{array}{l}\text { Engine: } \\
13624\end{array}$} & engine & 8652.4 & $59.85 \%$ \\
\cline { 2 - 4 } & motors & 2395.6 & $16.57 \%$ \\
\cline { 2 - 4 } Battery & wheels & 1216.9 & $8.42 \%$ \\
\cline { 2 - 4 } 832 & vehicle & 1238.9 & $8.57 \%$ \\
\cline { 2 - 4 } & battery & 708.32 & $4.9 \%$ \\
\cline { 2 - 4 } & clutches & 228.8 & $1.58 \%$ \\
\hline
\end{tabular}

\begin{tabular}{|c|c|c|c|}
\hline \multicolumn{3}{|c|}{ MP control strategy } \\
\hline $\begin{array}{c}\text { Power } \\
\text { sources } \\
{[\mathrm{KJ}]}\end{array}$ & \multicolumn{3}{|c|}{$\begin{array}{c}\text { Components loss } \\
\text { and } \\
\text { anoportion }\end{array}$} \\
\hline \hline \multirow{2}{*}{$\begin{array}{l}\text { Engine: } \\
11960\end{array}$} & engine & 7703.3 & $58.95 \%$ \\
\cline { 2 - 4 } & motors & 2062.5 & $15.78 \%$ \\
\cline { 2 - 4 } & wheels & 1219.1 & $9.33 \%$ \\
\cline { 2 - 4 } Battery: & vehicle & 1241.7 & $9.50 \%$ \\
\cline { 2 - 4 } 1106 & battery & 547.32 & $4.19 \%$ \\
\cline { 2 - 4 } & clutches & 278.65 & $2.13 \%$ \\
\hline
\end{tabular}

and $7703.3 \mathrm{KJ}$ under two control strategies, respectively. The engine loss is reduced by $949.1 \mathrm{KJ}$ under the MP control strategy compared with the OOL control strategy. Followed by the loss of two motors, respectively, accounting for $16.57 \%$ (2395.6 KJ) and $15.78 \%$ (2062.5 KJ) under two control strategies, and the loss of the motors is reduced by $333.1 \mathrm{KJ}$ after optimization. In addition, the energy loss of the vehicle body and the wheels is basically the same, mainly because the working condition and the vehicle parameters are the same. The energy loss of the battery during charge and discharge is about 4.9\% (708.32 KJ) under the OOL control strategy, and decreased by $161 \mathrm{KJ}$ under the MP control strategy, because the battery works in the most 
efficient area. Finally, the clutches also have energy losses during the opening and closing process, respectively, accounting for approximately $1.58 \%(228.8 \mathrm{KJ})$ and $2.13 \%(278.65 \mathrm{KJ})$, and can be ignored.

Simulation results demonstrate that the MP control strategy reduces fuel consumption by $10.9 \%$ and $9.46 \%$ compared with the OOL control strategy under the NEDC and UDDS conditions, respectively. The fuel economy is improved obviously.

\section{Conclusion}

Aiming at a power split hybrid electric vehicle with dual planetary gear sets, the system operation characteristics are analyzed using the lever analogy, and MG1 and MG2 are properly arranged. The relationship between the transmission efficiency and electric power ratio are analyzed, which provides a basis for the design of the control strategies.

The working modes of vehicles are divided, and steady speed and torque relations with the proposed power split system in several modes are analyzed theoretically. On this basis, the MP strategy is designed, where the engine speed control takes the mechanical point into consideration and the torque optimization of the engine is realized by a fuzzy controller. The HEV model is built based on AVL/Cruise software, the MP control strategy is built by the MATLAB/Simulink software. A co-simulation platform is established to conduct simulation studies.

The designed two control strategies are verified respectively. Simulation results show that two control strategies can both meet the expected targets. Compared with the OOL control strategy, the MP control strategy can reduce fuel consumption with a smaller fluctuation of the battery $S O C$, ensuring a high efficiency of the transmission system, and improving fuel economy of the proposed HEV.

Acknowledgement

This research is supported by The National Natural Science Foundation of China (grant No. 51475213), The National Key R\&D Plan (2017YFB0103200).

\section{References}

1. Andaloro L., Arista A., Agnello G., Napoli G., Sergi F., Antonucci V., 2017, Study and design of a hybrid electric vehicle (Lithium Batteries-PEMFC), International Journal of Hydrogen Energy, 42, 5, 3166-3184

2. Chen C., Liang T.T., 2011, Theoretic study of efficiency of two-DOFs of epicyclic gear transmission via virtual power, Journal of Mechanical Design, 133, 3, 031007

3. Du A., LiU K., Zhu Z., WANG C., 2015, Structure optimization of single-mode compound split hybrid power train, Chinese Mechanical Engineering, 26, 21, 2976-2981

4. Gupta A.K., Ramanarayanan C.P., 2013, Analysis of circulating power within hybrid electric vehicle transmissions, Mechanism and Machine Theory, 64, 131-143

5. Kang J., Choi W., Hong S., Park J., Kim H., 2011, Control strategy for dual-mode power split HEV considering transmission efficiency, Vehicle Power and Propulsion Conference, 1-6

6. KAng J., Choi W., Kim H., 2012, Development of a control strategy based on the transmission efficiency with mechanical loss for a dual mode power split-type hybrid electric vehicle, International Journal of Automotive Technology, 13, 5, 825-833

7. Kim J., Kang J., Kim Y., Kim T., Min B., Kim H., 2010, Design of power split transmission: design of dual mode power split transmission, International Journal of Automotive Technology, 11, $4,565-571$ 
8. Kiм N., Kiм J., Kıм H., 2008, Control of dual mode power split transmission for a hybrid electric vehicle, World Electric Vehicle Journal, 2

9. LANGLOis N., 2010, Optimized fuzzy logic control strategy of hybrid vehicles using ADVISOR, International Conference on Computer, 4, 444-447

10. Okamura M., Sato E., Sasaki S., 2003, Development of hybrid electric drive system using a boost converter, EVS-20, November

11. Schouten N.J., Salman M.A., Kheir N.A., 2002, Fuzzy logic control for parallel hybrid vehicles, IEEE Transactions on Control Systems Technology, 10, 3, 460-468

12. Schulz M., 2004, Circulating mechanical power in a power-split hybrid electric vehicle transmission, Drive System Technique, 218, 12, 1419-1425

13. SHeu K.B., 2008, Simulation for the analysis of a hybrid electric scooter powertrain, Applied Energy, 85, 7, 589-606

14. Song R.F., 2014, Research on Configuration Analyzing Methodology of Dual Mode Power-split Hybrid Powertrain (in Chinese), Jilin University

15. WAng W., 2014a, Control Algorithm Optimization of Power split HEV Based on Systematic Instantaneous Optimal, Jilin University

16. Wang W., Song R., Liu S., Zhai X., CaO Y., 2015, An analysis on the configuration of dualmode power-split hybrid powertrain system, Automotive Engineering, 6, 648-654

17. Wang W., Wang Q., Tian Y., Wang R., Wen Q., 2017, Control strategy for compound power split hybrid electric bus based on fuzzy control, Journal of Jilin University (Journal of Engineering)

18. Wang Z., 2014b, Configuration Analysis and Control Research for Dual-Planetary Gear HEV, Jilin University

19. Wishart J.D., Zhou L., Dong Z., 2007, Modelling and simulation of two-mode hybrid vehicle architecture, International Design Engineering Technical Conferences and Computers and Information in Engineering Conference, American Society of Mechanical Engineers, 1091-1112

20. Yao Y., 2016, Research on Power System Modeling and Control Strategy of Dual Planetary Gear Hybrid Electric Vehicle, Jiangsu University

21. Yin C., Pu J., Zhang J., 2006, The fuzzy torque control strategy for parallel hybrid electric vehicle, Journal of Shanghai Jiaotong University

22. Yu H., HuAng M., Deng C., 2007, Determination of optimal operating curve and efficient working area of parallel HEV engine, Shanghai Automobile, 7, 3-6

23. Yu H.S., Zhang J.W., Zhang T., 2012, Control strategy design and experimental research on a four-shaft electronic continuously variable transmission hybrid electric vehicle, Proceeding of the Institution of Mechanical Engineers Part D Journal of Automobile Engineering, 226, 12, 1594-1612

24. Zhang X., 2015, Analysis, Modeling and Simulation of Power Flow for Hybrid Electric Vehicle with Dual-Planetary Gear, Jiangsu University

25. Zhао B., MA D., 2014, Design and simulation of a new-type hybrid power split unit based on two planetary gear sets, Transmission Technology, 28, 1, 20-25

26. Zhuang W., Zhang X., Ding Y., Wang L., Hu X., 2016, Comparison of multi-mode hybrid powertrains with multiple planetary gears, Applied Energy, 178, 624-632 